\title{
Changes in Plasma Lipoproteins as Toxicity Markers for Carbon Tetrachloride, Chloroform, and Dichloromethane
}

\author{
Takeshi HONMA ${ }^{1 *}$ and Megumi SUDA ${ }^{2}$ \\ ${ }^{1}$ Department of Occupational Diseases, National Institute of Industrial Health, 6-21-1, Nagao, Tama-ku, Kawasaki \\ 214, Japan \\ ${ }^{2}$ Department of Industrial Physiology, National Institute of Industrial Health, 6-21-1, Nagao, Tama-ku, Kawasaki \\ 214, Japan
}

Received June 30, 1997 and accepted August 13, 1997

\begin{abstract}
Effects of single intraperitoneal (i.p.) administration of carbon tetrachloride $\left(\mathrm{CCl}_{4}\right)$, chloroform $\left(\mathrm{CHCl}_{3}\right)$, and dichloromethane $\left(\mathrm{CH}_{2} \mathrm{Cl}_{2}\right)$ on lipoproteins in plasma and liver were investigated in rats. Changes in lipoproteins caused by these solvents were compared with changes in traditional hepatotoxicity markers such as GPT (ALT). Following the administration, concentrations of lipoproteins (VLDL, LDL, HDL), triglyceride, cholesterol, and GPT activity in plasma were determined through changes in liver weight, liver content of triglyceride, malon dialdehyde (MDA), and glutathione (GSH). Time-course study revealed that changes in plasma and liver reached their peaks at 19 or $32 \mathrm{hr}$ following the administration of $\mathrm{CCl}_{4}$ or $\mathrm{CHCl}_{3}$. Peaks of changes were observed at 8 or $19 \mathrm{hr}$ following the administration of $\mathrm{CH}_{2} \mathrm{Cl}_{2}$. Dose dependency of these changes was investigated at dosages of 3, 30, and $300 \mathrm{mg} / \mathrm{kg}$ of $\mathrm{CCl}_{4}$ or $\mathrm{CHCl}_{3}$, and 300 , and $1,000 \mathrm{mg} / \mathrm{kg}$ of $\mathrm{CH}_{2} \mathrm{Cl}_{2}$. Significant decreases in triglyceride and apolipoproteins in VLDL fraction were observed at $3 \mathrm{mg} / \mathrm{kg}$ of $\mathrm{CCl}_{4}$. Such VLDL components decreased at $30 \mathrm{mg} / \mathrm{kg}$ of $\mathrm{CHCl}_{3}$. $\mathrm{HDL}$ decreased significantly at $300 \mathrm{mg} / \mathrm{kg}$ of $\mathrm{CH}_{2} \mathrm{Cl}_{2}$ and marked increase in LDL occurred at $1,000 \mathrm{mg} / \mathrm{kg}$ of the solvent. Liver weight and liver content of triglyceride and MDA significantly increased at $30 \mathrm{mg} / \mathrm{kg}$ of $\mathrm{CCl}_{4}$, while significant increase in GPT activity was observed at $300 \mathrm{mg} / \mathrm{kg}$ of $\mathrm{CCl}_{4}$ and $\mathrm{CHCl}_{3}$. GPT increased significantly at $1,000 \mathrm{mg} / \mathrm{kg} \mathrm{of} \mathrm{CH}_{2} \mathrm{Cl}_{2}$. These results revealed that changes in plasma lipoproteins can serve as sensitive and simple markers for liver disorders caused by chlorinated hydrocarbon solvents such as $\mathrm{CCl}_{4}, \mathrm{CHCl}_{3}, \mathrm{or}_{\mathbf{C H}_{2}} \mathrm{Cl}_{2}$.
\end{abstract}

Key words: Rat, Plasma, Lipoproteins, Toxicity markers, Carbon tetrachloride, Chloroform, Dichloromethane, Liver disorders

\section{Introduction}

Many chlorinated organic chemicals have been widely used

*To whom correspondence should be addressed.

Abbreviations: VLDL, very low density lipoproteins; LDL, low density lipoproteins; HDL, high density lipoproteins; d, density; PAGE, polyacrylamide gel electrophoresis; SDS, sodium dodesyl sulfate; EDTA, ethylenediaminetetraacetic acid; DTNB, 5,5'dithiobis (2-nitrobenzoic acid); GOT, Glutamic oxaloacetic transaminase; GPT, Glutamic pyruvic transaminase; MDA, malon dialdehyde; GSH, glutathione. for purposes such as industrial materials and degreasers ${ }^{1-3)}$. Since the use of chemicals such as chlorofluorocarbons and 1,1,1-trichloroethane is limited due to concerns about the ozone layer, the demand for dichloromethane $\left(\mathrm{CH}_{2} \mathrm{Cl}_{2}\right)$ as a cleaning solvent is increasing. For the same reason, the use of carbon tetrachloride $\left(\mathrm{CCl}_{4}\right)$ is limited and chloroform $\left(\mathrm{CHCl}_{3}\right)$ is being considered as an alternative solvent. $\mathrm{CHCl}_{3}$ is widely used in manufacturing plastics, drugs, and cleaning agents, while drinking water is frequently contaminated with 
$\mathrm{CHCl}_{3}$. Consequently, the need for toxicity evaluation of $\mathrm{CH}_{2} \mathrm{Cl}_{2}$ and $\mathrm{CHCl}_{3}$ has become more pronounced.

Many chlorinated hydrocarbon solvents, such as $\mathrm{CCl}_{4}$ and $\mathrm{CHCl}_{3}$, cause liver and kidney damage and brain disorders ${ }^{4-9}$. Although $\mathrm{CH}_{2} \mathrm{Cl}_{2}$ is regarded as less toxic than $\mathrm{CCl}_{4}$ and $\mathrm{CHCl}_{3}$, it exhibits hepatotoxicity and neurotoxicity ${ }^{10,11)}$. While many toxicity studies have been performed on $\mathrm{CCl}_{4}$, the toxicity of $\mathrm{CHCl}_{3}$ and $\mathrm{CH}_{2} \mathrm{Cl}_{2}$ has not been studied as extensively.

Liver damages from $\mathrm{CCl}_{4}$ is thought to be due to the breakdown of membrane structure caused by lipid peroxide, or the covalent binding of $\mathrm{CCl}_{4}$ metabolites with macromolecules in the liver" ${ }^{9}$ 12) $\mathrm{CHCl}_{3}$-induced liver damage is considered the result of phosgene formation ${ }^{13}$.

With exposure to highly toxic compounds such as $\mathrm{CCl}_{4}$, the concentrations of plasma lipoproteins decrease ${ }^{14,15)}$, likely the result of inhibition of synthesis or secretion of lipoproteins. These changes in lipoprotein metabolism appear to be produced by liver damage from hepatotoxins ${ }^{16-18)}$.

In previous reports, the authors described that changes in lipoproteins were observed following a single intraperitoneal (i.p.) administration of $\mathrm{CCl}_{4}$ and trichloroethylene ${ }^{19-21)}$. The doses at which these changes occurred were much lower than the doses which elevated the level of plasma transaminase, GOT (AST) and GPT (ALT) activities. These results suggest that changes in plasma lipoproteins can serve as sensitive markers for exposure to these chlorinated hydrocarbon solvents. Plasma concentration of VLDL was significantly reduced by $\mathrm{CCl}_{4}$ at a dosage of $30 \mathrm{mg} / \mathrm{kg}$, and significant liver enlargement was observed at the same dose of $\mathrm{CCl}_{4}$. In contrast to these findings, significant elevation of transaminase activity was not observed at 30 and 100 $\mathrm{mg} / \mathrm{kg}$. These facts suggest that changes in plasma lipoproteins can serve as markers for hepatotoxicity caused by inhalation exposure to chlorinated hydrocarbon solvents.

This paper aims to evaluate the toxicity of $\mathrm{CHCl}_{3}$ and $\mathrm{CH}_{2} \mathrm{Cl}_{2}$ relative to $\mathrm{CCl}_{4}$, and to pursue the possibility that plasma lipoproteins might be able to serve as hepatotoxicity markers for these chlorinated methane solvents, including $\mathrm{CCl}_{4}$.

\section{Materials and Methods}

\section{Animals}

Male Fischer 344 rats, between 12 to 16 weeks-old (Japan Charles River) were used in this study. All subjects were group housed in cages made with stainless steel wire net and provided with ready access to food (CE-2, Nihon Clea,
Japan) and water under a 12:12 hr light:dark cycle with lights being turned on at 8:00 a.m. prior to testing. The room was maintained at $23 \pm 1{ }^{\circ} \mathrm{C}$ and $55 \pm 5 \%$ relative humidity. In each experiment, the ages of the rats were within 3 days of each other. This investigation was performed in accordance with the principles of the Declaration of Helsinki, and followed a guideline approved by the Institutional Animal Care and Use Committee of the National Institute of Industrial Health.

\section{Solvent administration}

The solvents used were $\mathrm{CCl}_{4}$ (specially prepared for spectroscopy, Nacalai tesque Inc., Japan), $\mathrm{CHCl}_{3}$ (ultrafine grade, Nacalai), and $\mathrm{CH}_{2} \mathrm{Cl}_{2}$ (pesticide residue grade, Wako Pure Chemicals, Japan). These organic solvents were dissolved in $1 \mathrm{ml}$ of olive oil $/ \mathrm{kg}$ body weight, and injected intraperitoneally (i.p.). Control animals were treated with the same volume of olive oil. Chemicals were administered between 2:00 p.m. and 4:00 p.m., and rats were starved from 10:00 a.m. on the day of administration. However, tap water was allowed ad libitum.

\section{Preparation of lipoprotein fractions}

Under light anesthesia with diethylether, the rats were exsanguinated via the abdominal vein. Blood plasmas containing $1 \mathrm{mg}$ of EDTA $/ \mathrm{ml}$ were separated by centrifugation. To each plasma sample used for separation of lipoprotein fractions were added $0.1 \mathrm{mg}$ of sodium azide/ $\mathrm{ml}$, and $0.01 \mathrm{mg}$ of DTNB/ml. Sodium azide and DTNB were used as fungicide and lipase inhibitor, respectively.

The various lipoprotein fractions in plasmas were separated by preparative ultracentrifugation using a RP-50AT 4 rotor (Hitachi, Japan) at $48,000 \mathrm{rpm}(270,000 \mathrm{~g})$ in a SCP-70H ultracentrifuge (Hitachi) at $10^{\circ} \mathrm{C}$. The ultracentrifugation was performed immediately after the plasma sampling. The density of the plasma samples was adjusted by adding $\mathrm{NaBr}$ solutions. The plasmas were pipetted into ultracentrifuge tubes, and filled up to $3.3-\mathrm{ml}$ with a d 1.006 solution containing $0.15 \mathrm{M} \mathrm{NaCl}, 0.1 \%$ EDTA, $0.01 \%$ sodium azide, and $0.001 \%$ DTNB (END mixture), and centrifuged for 16 $\mathrm{hr}$. The top $1.0 \mathrm{ml}$ containing VLDL was carefully removed as VLDL fraction. The density in the tube was adjusted to 1.063 by adding high density $\mathrm{NaBr}$ solution containing END mixture. After centrifuging for $16 \mathrm{hr}$, the top $1.0 \mathrm{ml}$ was removed as LDL fraction. The LDL fraction that was obtained by ultracentrifugation of rat plasma at $d 1.063$ contains $\mathrm{LDL}$ and $\mathrm{HDL}_{1}$, and these two lipoproteins could not be separated in any density range. To isolate HDL 
fraction, the density was raised to 1.210 , and the top $1.0 \mathrm{ml}$ was removed after centrifuging for $22 \mathrm{hr}$. The HDL fraction thus obtained contained $\mathrm{HDL}_{2}$. Each lipoprotein fraction was stored at $-50^{\circ} \mathrm{C}$ until analysis, except the plasma and LDL fraction used for native PAGE (polyacrylamide gel electrophoresis).

\section{Electrophoresis of lipoproteins}

Plasmas and LDL fraction were applied to native 2-15\% gradient PAGE immediately after the preparation, and lipoproteins in the electrophoresis gel were stained with Oil Red O (BHD Chemicals, England). Lipid staining density was measured at $530 \mathrm{~nm}$ using a TLC scanner (CS-910, Shimadzu, Kyoto). In time-course study, plasmas were applied to native PAGE, and three broad bands of VLDL, LDL, and HDL were obtained. In this PAGE, LDL band was composed of LDL, and HDL band was composed of $\mathrm{HDL}_{1}$ and $\mathrm{HDL}_{2}$ because these two HDL subclasses could not be separated. In dose-effect relationship study, LDL fraction obtained at $d 1.063$ through ultracentrifugation was applied to native PAGE. By the application of LDL fraction, two bands of $\mathrm{LDL}$ and $\mathrm{HDL}_{1}$ were obtained. Concentrations of these two lipoproteins thus separated were determined by measuring the lipid staining density. Apolipoproteins in each lipoprotein fraction were analyzed by SDS 4-28\% gradient PAGE. Each apolipoprotein in the electrophoresis gel was stained with Coomassie Brilliant blue R 250, and the staining density was determined at $555 \mathrm{~nm}$ using a flyingspot scanner (CS-9000, Shimadzu). By application of VLDL fraction to SDS PAGE, apolipoprotein bands Bl, Bs, E's, and C's were obtained. Application of LDL fraction to SDS PAGE produced three apolipoprotein bands. Of these bands, $\mathrm{Bl}$ and $\mathrm{Bs}$ are components of LDL and E's are components of $\mathrm{HDL}_{1}$. SDS PAGE of HDL fraction offered many apolipoprotein bands, and the main components were A-I, E's, C's, and A-IV.

\section{Biochemical analysis}

The plasma, each lipoprotein fraction, and liver were analyzed for lipids by enzymatic procedures, as early on in the process as possible. Triglyceride, total cholesterol, and phospholipid were measured using Determiner TG-S555 ${ }^{\circledR}$ (Kyowa Medex, Japan), Monotest cholesterol ${ }^{\circledR}$ (Boeringer mannheim, Germany), and PL Kainos ${ }^{\circledR}$ (Kainos Laboratories, Japan) kits, respectively. Liver lipids were extracted with methanol-chloroform mixture by the method reported by Folch $^{22)}$. Plasma GPT activity was determined using a Monotest GPT ${ }^{\circledR}$ (Boeringer mannheim) kit. Liver malondialdehyde (MDA) was confirmed as an indicator of lipid peroxide formation with a colorimetric assay developed by Yagi ${ }^{23)}$. Liver total, reduced + oxidized, glutathione (GSH) was measured using glutathione reductase ${ }^{24}$. The protein contents of each lipoprotein fraction were estimated using a modified Lowry method ${ }^{25}$.

\section{Statistical analysis}

Differences among the three or four groups were analyzed by analysis of variance (F-test). Dunnett's multiple $t$-test was also used to compare the control and the solvent-treated groups. A p-value of $<0.05$ was chosen to indicate significance.

\section{Results}

\section{Time-course study}

The time-course of the effects of solvent administration were investigated with each of three chlorinated organic compounds. Figures 1A, 1B, and 1C show the time-course changes in lipoproteins (VLDL, LDL, and HDL), plasma lipids (triglyceride and cholesterol), GPT activity, and liver (liver weight, triglyceride, MDA, and GSH) after an i.p. administration of $\mathrm{CCl}_{4}$ at a dose of $10 \mathrm{mg} / \mathrm{kg}$. Rats were sacrificed 8,19 , and $32 \mathrm{hr}$ following the administration. Figure 1A shows the density of lipid staining of lipoproteins, which was obtained by applying rat plasmas to native PAGE. Plasma concentrations of VLDL, LDL, and HDL decreased in administered rats and statistical significance between control and dosed groups was obtained in all 3 lipoproteins, as observed in Figure 1A. Differences between control and dosed groups were largest 19 or $32 \mathrm{hr}$ after the administration. Figure 1B shows plasma concentrations of triglyceride and cholesterol, and GPT activity. Triglyceride and cholesterol decreased in dosed rats, but no change in GPT activity was observed. The largest difference between control and dosed group in triglyceride and cholesterol was obtained at 19 or $32 \mathrm{hr}$. Figure $1 \mathrm{C}$ shows liver-to-body weight ratios, triglyceride contents of the liver, MDA and GSH concentrations in the liver. Liver weight, triglyceride, and MDA increased in administered rats, although the increases in triglyceride was not significant. Differences between the control and dosed groups in these items were largest 19 or $32 \mathrm{hr}$ after the administration.

Figures $2 \mathrm{~A}, 2 \mathrm{~B}$, and $2 \mathrm{C}$ demonstrate the time-course changes in plasma substances and liver of rats received i.p. administration of $\mathrm{CHCl}_{3}$ at $100 \mathrm{mg} / \mathrm{kg}$. Measurements were performed 8, 19, and $32 \mathrm{hr}$ after the administration. Plasma 
A

VLDL-Lipid

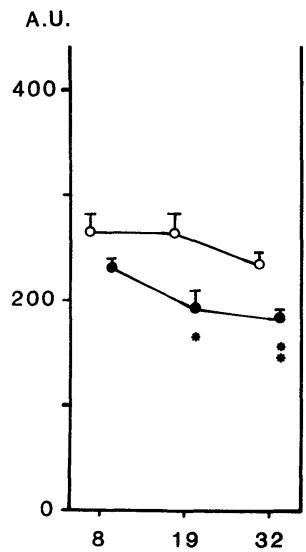

B

Plasma TG

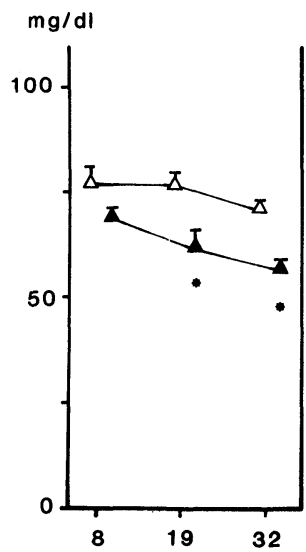

LDL-Lipid

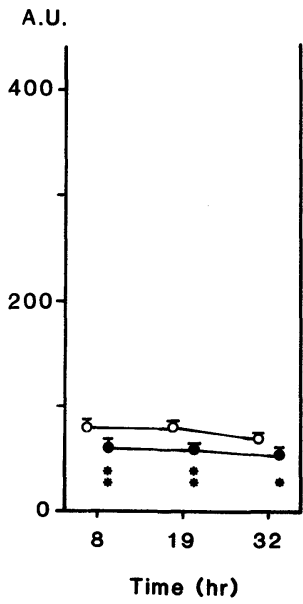

Plasma Chol

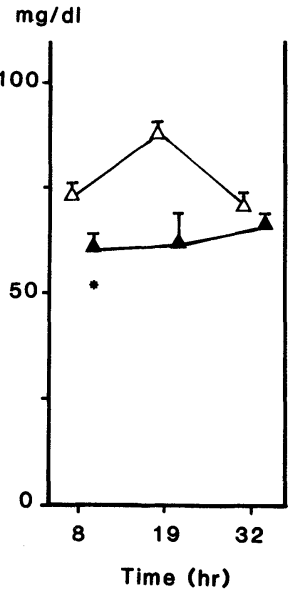

HDL-Lipid

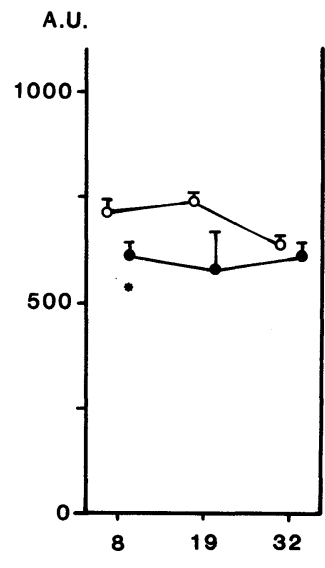

Plasma GPT

IU/L

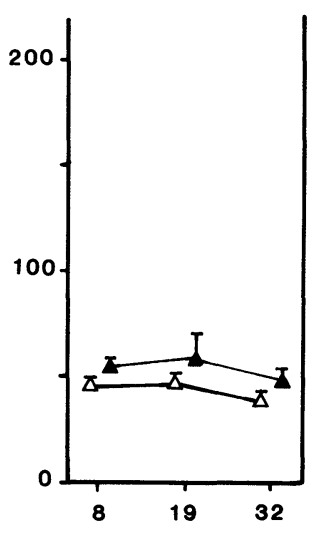

Fig. 1A. Time-course changes in the plasma concentrations of VLDL, LDL, and HDL fractions following $10 \mathrm{mg} / \mathrm{kg}$ i.p. $\mathrm{CCl}_{4}$ injections to rats Open circles: control groups; closed circles: injected groups. Each point is the mean \pm SEM (vertical bar) for 4 rats. $*$ and $* *$ represent statistically significant differences from correspondent control at $\mathrm{p}<0.05$ and $\mathrm{p}<0.01$, respectively, by Student's $t$-test. A.U.: arbitrary units for the staining density of the lipid staining of the electrophoresis gel.

Fig. 1B. Time-course changes in the plasma concentrations of triglyceride, cholesterol, and GPT following $10 \mathrm{mg} / \mathrm{kg}$ i.p. $\mathrm{CCl}_{4}$ injections to rats TG: triglyceride; chol: cholesterol. Open triangles: control groups; closed triangles: injected groups. Other legends are as in Fig. 1A.

Fig. 1C. Time-course changes in liver weight, liver triglyceride, liver malondialdehyde, and liver glutathione following $10 \mathrm{mg} / \mathrm{kg}$ i.p. $\mathrm{CCl}_{4}$ injections to rats

TG: triglyceride; MDA: malondialdehyde; GSH: reduced and oxidized glutathione. Open squares: control groups; closed squares: injected groups. Liver weight was obtained as percent value of the body weight. TG contents are mg per whole liver. MDA and GSH contents were obtained as the amount per $g$ tissue weight of the liver. Other legends are as in Fig. 1A.

C

Liver Weight

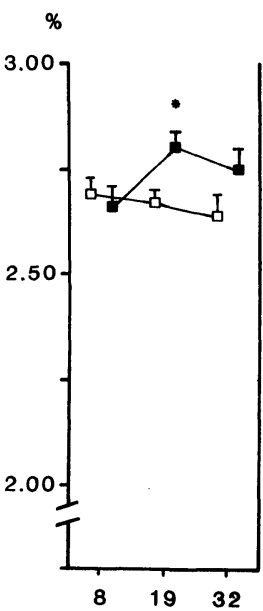

Liver TG

Liver MDA

Liver GSH

$\mathrm{mg} /$ live

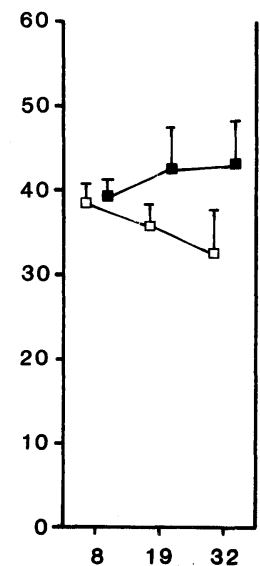

nmoles/gliver

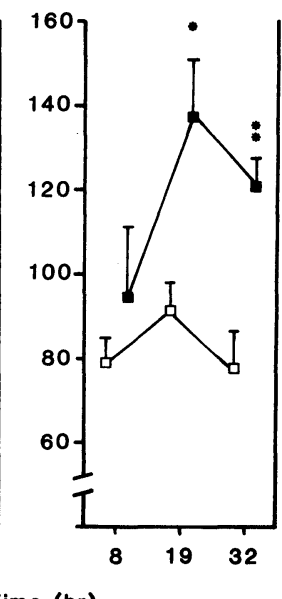

umoles/gliver

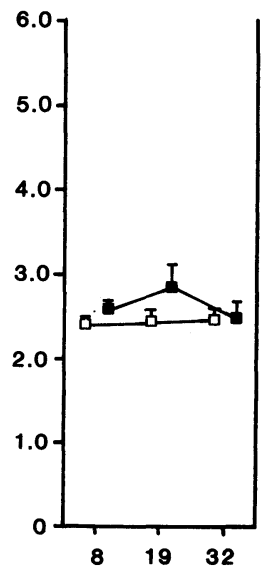


VLDL was reduced by the $\mathrm{CHCl}_{3}$ administration at all measurement point (Fig. 2A). The largest difference of VLDL between the control and dosed groups was observed $19 \mathrm{hr}$ after the administration. LDL was reduced by $\mathrm{CHCl}_{3}$ at 8 $\mathrm{hr}$ but unchanged at 19 and $32 \mathrm{hr}$. HDL was reduced in the administrated group but statistical significance was not obtained. Triglyceride and cholesterol in plasma was reduced and statistical significance was obtained at $19 \mathrm{hr}$ after (Fig. 2B). Plasma GPT activity was raised at 19 and $32 \mathrm{hr}$ and the most marked increase was observed at $19 \mathrm{hr}$. Liver weight increased at 19 and $32 \mathrm{hr}$ and the increase at $32 \mathrm{hr}$ was significant (Fig. 2C). Hepatic triglyceride content, and MDA and GSH concentrations in the liver increased at 19 and 32 $\mathrm{hr}$; however, these increases were not significant. The largest differences in liver weight, triglyceride, and GSH between the control and administered groups were observed at 19 hr. The largest difference of MDA was observed at $32 \mathrm{hr}$.

Figures $3 \mathrm{~A}, 3 \mathrm{~B}$, and $3 \mathrm{C}$ show the effects of the administration of $\mathrm{CH}_{2} \mathrm{Cl}_{2}$ at $600 \mathrm{mg} / \mathrm{kg}$. The measurement was performed 4,8 , and $19 \mathrm{hr}$ after the solvent administration. Plasma VLDL levels were lower in injected rats than in control subjects (Fig. 3A). The lowest VLDL level was obtained $8 \mathrm{hr}$ after the injection. LDL was increased in injected groups, and the maximum increase was obtained at $8 \mathrm{hr}$. $\mathrm{HDL}$ was decreased by $\mathrm{CH}_{2} \mathrm{Cl}_{2}$ and significant differences in plasma HDL concentrations between the control and injected groups was observed $19 \mathrm{hr}$ after the administration. Plasma triglyceride and cholesterol levels in the injected groups were lower than those in the control groups at 8 and $19 \mathrm{hr}$, but these differences were not significant (Fig. 3B). GPT activity was raised by the $\mathrm{CH}_{2} \mathrm{Cl}_{2}$ injection, and maximum increase was observed at $8 \mathrm{hr}$. Liver weight was reduced by the injection, and was minimal at $8 \mathrm{hr}$ (Fig. 3C). No significant change in triglyceride content and MDA concentration was observed. GSH was reduced significantly at $8 \mathrm{hr}$.

\section{Dose-effect relationships}

Effects of different doses of $\mathrm{CCl}_{4}, \mathrm{CHCl}_{3}$, and $\mathrm{CH}_{2} \mathrm{Cl}_{2}$ on plasma lipoprotein and lipid concentrations, and GPT activity were measured. Changes in liver weight, and triglyceride, MDA, and GSH in the liver were investigated. Rats were administered with $\mathrm{CCl}_{4}$ at dosages of 3,30 or $300 \mathrm{mg} / \mathrm{kg}$. Changes in plasma and liver were measured $19 \mathrm{hr}$ after the administration and results are summarized in Tables $1 \mathrm{~A}$, 1B, 1C, and 1D. Table 1A shows changes in lipid and apolipoprotein components of VLDL fraction. Most of the components of VLDL was triglyceride, and the ratios of protein, cholesterol, and phospholipid were very small.
Triglyceride, total protein, and apolipoprotein C's in VLDL fraction decreased significantly at $3 \mathrm{mg} / \mathrm{kg}$. VLDLtriglyceride decreased to $77 \%$ of control level. Apolipoprotein Bl, Bs, and E's also decreased, although no statistical significance was obtained. All components of VLDL were reduced at 30 and $300 \mathrm{mg} / \mathrm{kg}$ with statistical significance. At $300 \mathrm{mg} / \mathrm{kg}$, levels of all components were $31 \%$ of the control or less. Table 1B shows the changes in LDL fraction. In lipoprotein separation from rat plasma using ultracentrifugation, LDL were always accompanied with $\mathrm{HDL}_{1}$ and it was impossible to obtain pure LDL in any density range. Therefore, LDL fraction prepared in ultracentrifugation contained both $\mathrm{LDL}$ and $\mathrm{HDL}_{1}$, which were separated on electrophoresis gel. Lipids in these lipoproteins were stained with Oil Red $\mathrm{O}$ and the staining density is shown in Table 1B. LDL contains only $\mathrm{Bl}$ and $\mathrm{Bs}$ as apolipoprotein components. $\mathrm{HDL}_{1}$ contains only E's as apolipoproteins. Therefore, apolipoprotein components of LDL and $\mathrm{HDL}_{1}$ could be quantitated separately on SDS PAGE gel, although LDL fraction contained both LDL and $\mathrm{HDL}_{1}$. As shown in Table 1B, LDL lipid, apolipoproteins Bl and Bs increased with no significance at $3 \mathrm{mg} / \mathrm{kg}$. At $30 \mathrm{mg} / \mathrm{kg}$, levels of LDL components were between 51 and $60 \%$ of the control, while at $300 \mathrm{mg} / \mathrm{kg}$, levels of these components were between 46 and $55 \%$ of the control. Three $\mathrm{mg} / \mathrm{kg}$ of $\mathrm{CCl}_{4}$ produced no change in $\mathrm{HDL}_{1}$ lipid and apolipoprotein E's. Thirty $\mathrm{mg} / \mathrm{kg}$ of the solvent decreased these $\mathrm{HDL}_{1}$ components to 58 , or $69 \%$ of the control. At $300 \mathrm{mg} / \mathrm{kg}$, these components decreased to 30 , or $43 \%$ of the control. Total protein of LDL fraction ( $\left.\mathrm{LDL}+\mathrm{HDL}_{1}\right)$ was reduced significantly at 30 and $300 \mathrm{mg} / \mathrm{kg}$. Table $1 \mathrm{C}$ shows the effects of $\mathrm{CCl}_{4}$ on $\mathrm{HDL}$ fraction $\left(\mathrm{HDL}_{2}\right)$. Among the components of HDL fraction, the ratio of triglyceride was very small. Components of HDL fraction except cholesterol increased slightly at $3 \mathrm{mg} / \mathrm{kg}$, while they were reduced to 51 , or $88 \%$ of the control at $30 \mathrm{mg} / \mathrm{kg}$, and reduced to 41 , or $55 \%$ of the control at $300 \mathrm{mg} / \mathrm{kg}$ (Table 1C). Table 1D summarizes changes in plasma components and the liver. Plasma triglyceride and cholesterol concentrations decreased at 30 $\mathrm{mg} / \mathrm{kg}$ or more. Significant increase in GPT was observed at $300 \mathrm{mg} / \mathrm{kg}$. Liver weight, triglyceride content, and MDA concentration in the liver increased significantly at $30 \mathrm{mg} /$ $\mathrm{kg}$ or more, while increases in cholesterol, phospholipid, and GSH were not significant. Phospholipid content and GSH concentration increased significantly at $300 \mathrm{mg} / \mathrm{kg}$. To ascertain the effects of olive oil administration on plasma lipids, two rats were injected i.p. with olive oil at a dosage of $1 \mathrm{ml} / \mathrm{kg}$, and the other two rats received no treatment 
A

VLDL-Lipid

A.U.

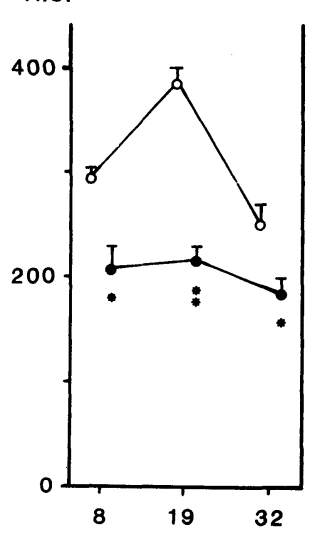

B

Plasma TG

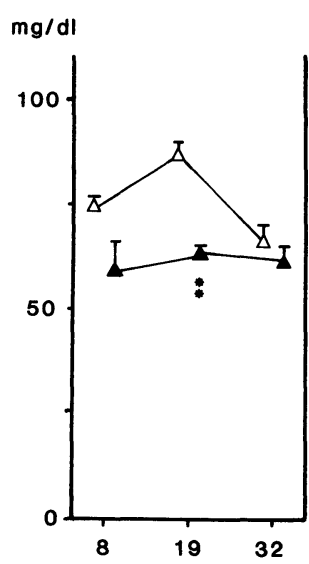

LDL-Lipid
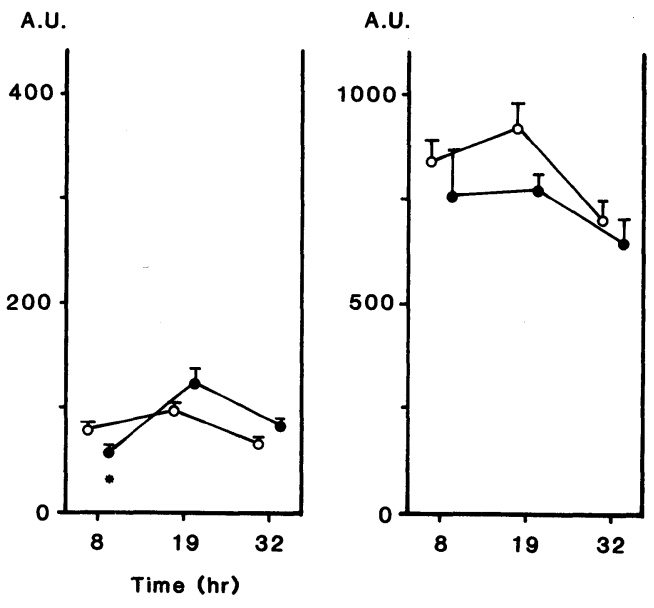

Fig. 2A. Time-course changes in the plasma concentrations of VLDL, LDL, and HDL fractions following $100 \mathrm{mg} / \mathrm{kg}$ i.p. $\mathrm{CHCl}_{3}$ injections to rats Legends are as in Fig. 1A.

Fig. 2B. Time-course changes in the plasma concentrations of triglyceride, cholesterol, and GPT following $100 \mathrm{mg} / \mathrm{kg}$ i.p. $\mathrm{CHCl}_{3}$ injections to rats Legends are as in Fig. 1B.

Fig. 2C. Time-course changes in the liver weight, liver triglyceride, liver malondialdehyde, and liver glutathione following $100 \mathrm{mg} / \mathrm{kg}$ i.p. $\mathrm{CHCl}_{3}$ injections to rats

Legends are as in Fig. 1C.

C
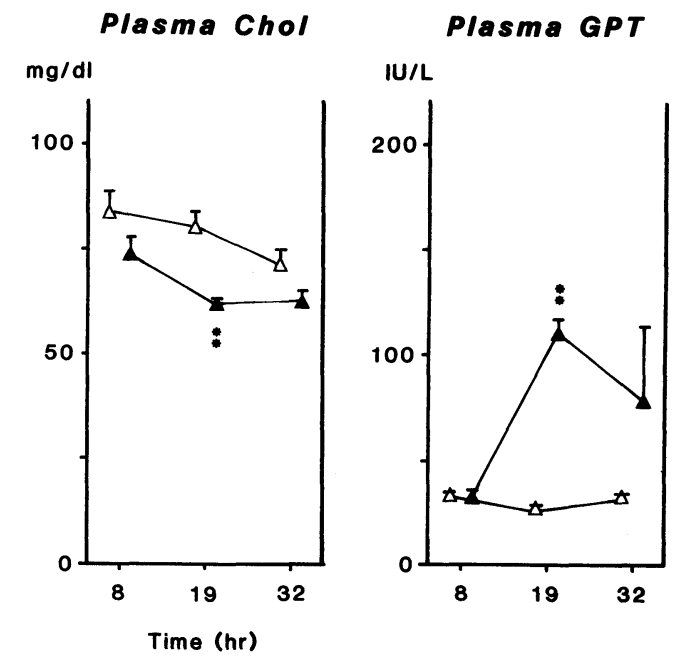

Liver Weight

Liver TG

Liver MDA

Liver GSH
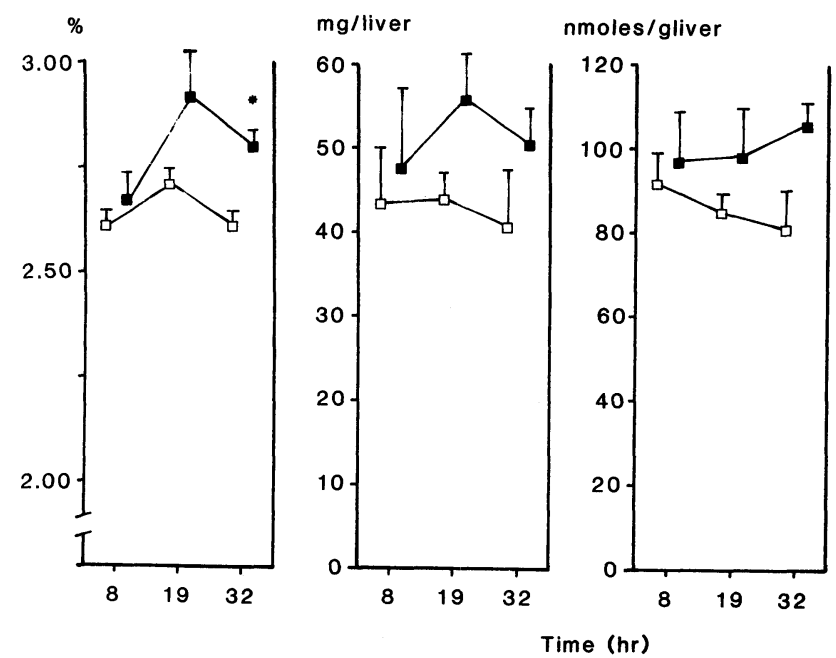

umoles/gliver

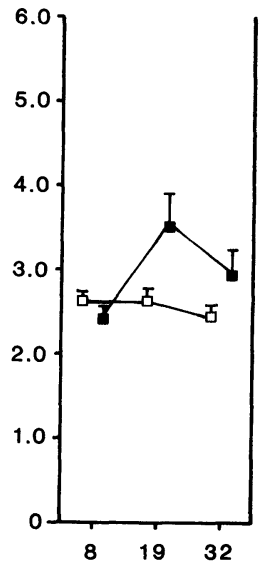


$\mathbf{A}$

VLDL-Lipid

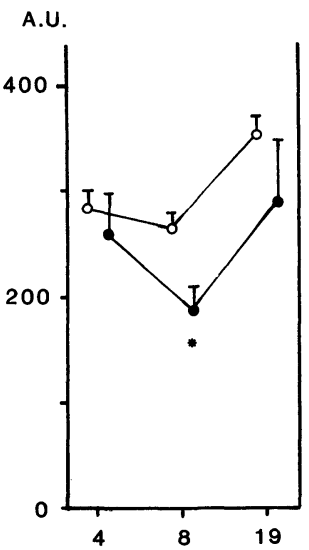

B

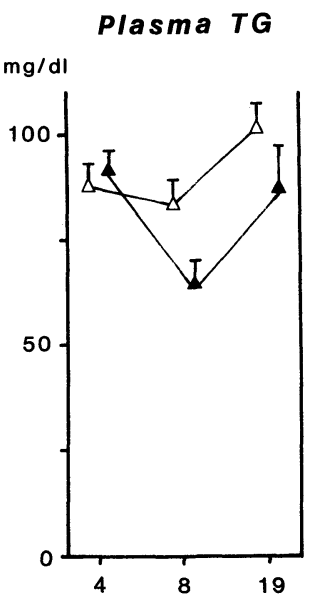

LDL-Lipid

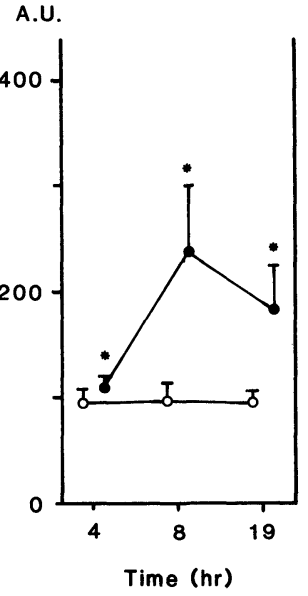

Plasma Chol

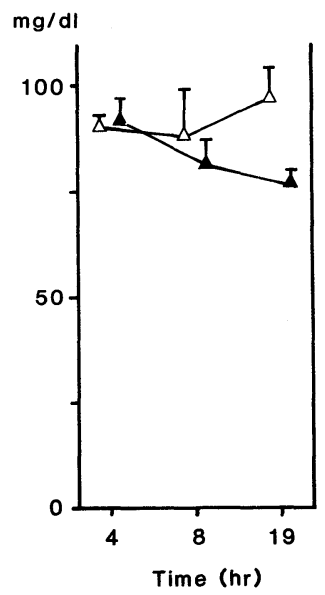

HDL-Lipid

A.U.

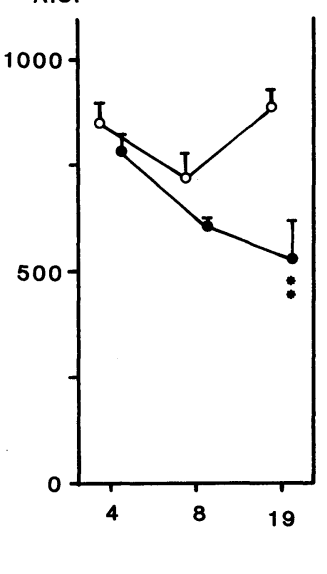

Plasma GPT

IU/L

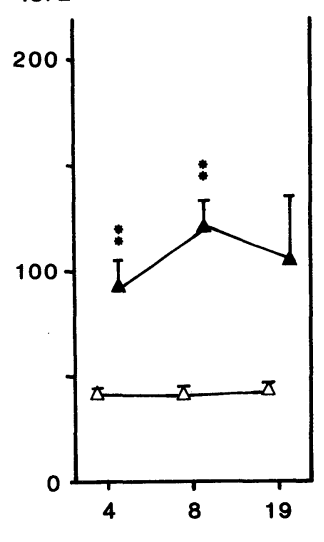

Fig. 3A. Time-course changes in the plasma concentrations of VLDL, LDL, and HDL fractions following $600 \mathrm{mg} / \mathrm{kg}$ i.p. $\mathrm{CH}_{2} \mathrm{Cl}_{2}$ injections to rats Legends are as in Fig. 1A.

Fig. 3B. Time-course changes in the plasma concentrations of triglyceride, cholesterol, and GPT following $600 \mathrm{mg} / \mathrm{kg}$ i.p. $\mathrm{CH}_{2} \mathrm{Cl}_{2}$ injections to rats Legends are as in Fig. 1B.

Fig. 3C. Time-course changes in the liver weight, liver triglyceride, liver malondialdehyde, and liver glutathione following $600 \mathrm{mg} / \mathrm{kg}$ i.p. $\mathrm{CH}_{2} \mathrm{Cl}_{2}$ injections to rats

Legends are as in Fig. 1C.

C

Liver Weight

Liver TG

Liver MDA

Liver GSH
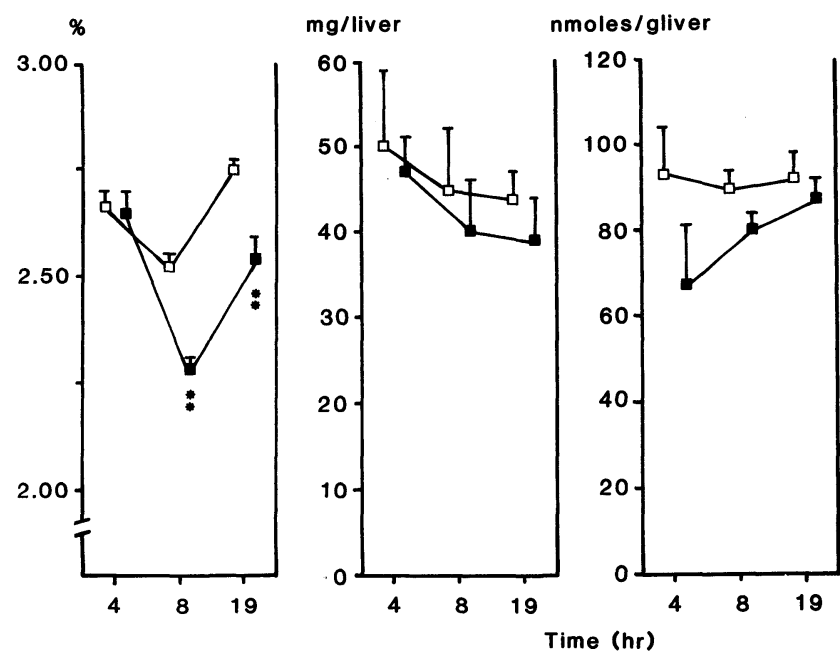

umole/gliver

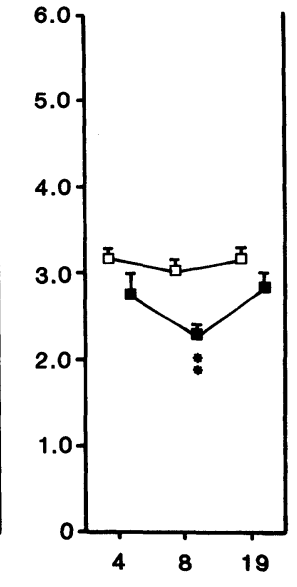


Table 1A. Effects of a single administration of $\mathrm{CCl}_{4}$ on the plasma VLDL fraction of rats

\begin{tabular}{lcccrcr}
\hline \multicolumn{1}{c}{ Dose (mg/kg) } & F-test & 0 & 3 & 30 & 300 \\
\hline TG (mg/dl plasma) & $\mathrm{p}<0.01$ & $63.3 \pm 4.4$ & $49.0 \pm 3.0(77)^{*}$ & $32.0 \pm 3.9(51)^{\#}$ & $19.5 \pm 1.8(31)^{\#}$ \\
PR (mg/dl plasma) & $\mathrm{p}<0.01$ & $12.5 \pm 0.6$ & $10.4 \pm 0.5(83)^{\#}$ & $4.6 \pm 0.2(37)^{\#}$ & $1.5 \pm 0.2(12)^{\#}$ \\
Apo Bl (A.U.) & $\mathrm{p}<0.01$ & $26.0 \pm 1.2$ & $24.5 \pm 2.3(94)$ & $11.5 \pm 1.4(44)^{\#}$ & $7.8 \pm 1.7(30)^{\#}$ \\
Apo Bs (A.U.) & $\mathrm{p}<0.01$ & $30.3 \pm 2.2$ & $29.0 \pm 0.8(96)$ & $16.5 \pm 1.2(54)^{\#}$ & $6.0 \pm 1.1(20)^{\#}$ \\
Apo E's (A.U.) & $\mathrm{p}<0.01$ & $209.3 \pm 13.3$ & $190.8 \pm 16.1(91)$ & $124.3 \pm 10.8(59)^{\#}$ & $17.3 \pm 3.6(8)^{\#}$ \\
Apo C's (A.U.) & $\mathrm{p}<0.01$ & $105.5 \pm 4.2$ & $91.0 \pm 4.1(86)^{*}$ & $37.3 \pm 2.3(35)^{\#}$ & $12.0 \pm 3.0(11)^{\#}$ \\
\hline
\end{tabular}

TG, triglyceride. PR, protein. Apo, apolipoprotein. A.U., arbitrary units for staining density of protein staining in electrophoresis gel. Each value represents the mean $\pm \mathrm{SEM}(\mathrm{N}=6)$. * and ${ }^{*}$ represent significant differences at $0.05>\mathrm{p}$ and $0.01>\mathrm{p}$, respectively, between the control and solvent-treated groups by Dunnett's test. n.s., $\mathrm{p}<0.05$, and $\mathrm{p}<0.01$ in the table represent not significant, significant at $0.05>\mathrm{p}$, and significant at $0.01>\mathrm{p}$, respectively, by the analysis of variance (F-test). Percent values of the exposed group when control value was set at $100 \%$ are shown in parenthesis.

Table 1B. Effects of a single administration of carbon tetrachloride on the plasma LDL fraction of rats

\begin{tabular}{lccccc}
\hline Dose (mg/kg) & F-test & 0 & 3 & 30 & 300 \\
\hline LDL & & & & & \\
$\quad$ Lipid (A.U.) & $\mathrm{p}<0.01$ & $184.3 \pm 7.4$ & $206.3 \pm 9.4(112)$ & $110.8 \pm 12.0(60)^{\#}$ & $102.0 \pm 3.5(55)^{\#}$ \\
$\quad$ Apo Bl (A.U.) & $\mathrm{p}<0.01$ & $110.3 \pm 6.5$ & $137.5 \pm 12.0(125)$ & $56.5 \pm 11.4(51)^{\#}$ & $54.8 \pm 6.7(50)^{\#}$ \\
$\quad$ Apo Bs (A.U.) & $\mathrm{p}<0.01$ & $21.3 \pm 2.2$ & $27.0 \pm 2.1(127)$ & $12.8 \pm 0.9(60)^{\#}$ & $9.8 \pm 1.0(46)^{\#}$ \\
HDL & & & & & \\
$\quad$ Lipid (A.U.) & $\mathrm{p}<0.01$ & $91.3 \pm 4.7$ & $86.5 \pm 3.5(95)$ & $53.3 \pm 5.3(58)^{\#}$ & $27.5 \pm 2.1(30)^{\#}$ \\
$\quad$ Apo E's (A.U.) & $\mathrm{p}<0.01$ & $148.0 \pm 6.3$ & $138.5 \pm 6.0(94)$ & $102.5 \pm 9.7(69)^{\#}$ & $63.8 \pm 5.7(43)^{\#}$ \\
LDL + HDL & & & & & \\
PR (mg/dl plasma) & $\mathrm{p}<0.01$ & $2.3 \pm 0.1$ & $2.5 \pm 0.2(109)$ & $1.6 \pm 0.1(70)^{\#}$ & $1.4 \pm 0.1(61)^{\#}$ \\
\hline
\end{tabular}

A.U., Arbitrary units for staining density of lipid staining for $\mathrm{LDL}$ and $\mathrm{HDL}_{1}$, or protein staining for apolipoproteins in electrophoresis gel. Other legends are as in Table 1A.

Table 1C. Effects of a single administration of carbon tetrachloride on the plasma HDL fraction of rats

\begin{tabular}{lcccccc}
\hline \multicolumn{1}{c}{ Dose (mg/kg) } & F-test & 0 & 3 & 30 & 300 \\
\hline CH (mg/dl plasma) & $\mathrm{p}<0.01$ & $19.8 \pm 1.4$ & $17.8 \pm 1.8(90)$ & $10.5 \pm 1.7(53)^{\#}$ & $8.5 \pm 1.0(43)^{\#}$ \\
PL (mg/dl plasma) & $\mathrm{p}<0.01$ & $21.5 \pm 1.8$ & $23.3 \pm 2.9(108)$ & $15.3 \pm 1.4(71)$ & $11.8 \pm 0.9(55)^{\#}$ \\
PR (mg/dl plasma) & $\mathrm{p}<0.01$ & $61.8 \pm 4.9$ & $68.3 \pm 4.8(111)$ & $46.8 \pm 3.8(76)$ & $30.8 \pm 1.7(50)^{\#}$ \\
Apo A-IV (A.U.) & $\mathrm{p}<0.01$ & $218 \pm 11$ & $248 \pm 11(114)$ & $111 \pm 8$ & $(51)^{\#}$ & $104 \pm 13(48)^{\#}$ \\
Apo E's (A.U.) & $\mathrm{p}<0.01$ & $966 \pm 63$ & $1,122 \pm 45(116)$ & $630 \pm 50(65)^{\#}$ & $398 \pm 22(41)^{\#}$ \\
Apo A-I (A.U.) & $\mathrm{p}<0.01$ & $1,903 \pm 109$ & $2,260 \pm 152(119)$ & $1,670 \pm 114(88)$ & $1,052 \pm 61(55)^{\#}$ \\
Apo C's (A.U.) & $\mathrm{p}<0.01$ & $452 \pm 49$ & $509 \pm 32 \quad(113)$ & $311 \pm 25(69)^{*}$ & $200 \pm 12(44)^{\#}$ \\
\hline
\end{tabular}

$\mathrm{CH}$, cholesterol; PL, phospholipid. Other legends are as in Table 1A.

Table 1D. Effects of a single administration of carbon tetrachloride on plasma lipid contents, GPT activity, and liver of rats

\begin{tabular}{|c|c|c|c|c|c|c|}
\hline Dose (mg/kg) & F-test & 0 & 3 & 30 & 300 & \\
\hline \multicolumn{7}{|l|}{ Plasma } \\
\hline TG (mg/dl plasma) & $\mathrm{p}<0.01$ & $89.5 \pm 6.0$ & $85.3 \pm 4.9 \quad(95)$ & $55.3 \pm 5.4(62)^{\#}$ & $35.5 \pm 4.2$ & $(40)^{\#}$ \\
\hline $\mathrm{CH}(\mathrm{mg} / \mathrm{dl}$ plasma $)$ & $\mathrm{p}<0.01$ & $47.5 \pm 1.8$ & $48.0 \pm 1.5$ & $31.5 \pm 2.5 \quad(66)^{\#}$ & $25.5 \pm 0.6$ & $(54)^{\#}$ \\
\hline GPT (IU/L) & $\mathrm{p}<0.01$ & $34.8 \pm 2.4$ & $34.3 \pm 2.9$ ( 99$)$ & $56.8 \pm 6.5$ & $745.8 \pm 103.5$ & $(2143)^{\#}$ \\
\hline \multicolumn{7}{|l|}{ Liver } \\
\hline Weight (\%) & $\mathrm{p}<0.01$ & $2.64 \pm 0.06$ & $2.74 \pm 0.01(104)$ & $3.01 \pm 0.04(114)^{\#}$ & $3.25 \pm 0.02$ & $(123)^{\#}$ \\
\hline TG (mg/liver) & $\mathrm{p}<0.01$ & $66.0 \pm 2.7$ & $76.0 \pm 3.6$ & $109.0 \pm 5.6(165)^{*}$ & $145.8 \pm 15.6$ & $(221)^{\#}$ \\
\hline $\mathrm{CH}$ (mg/liver) & $\mathrm{p}<0.05$ & $34.3 \pm 1.9$ & $32.8 \pm 0.9(96)$ & $38.5 \pm 2.0$ & $41.5 \pm 2.7$ & $(121)$ \\
\hline PL (mg/liver) & $\mathrm{p}<0.05$ & $69.0 \pm 3.8$ & $70.0 \pm 1.8$ & $73.5 \pm 1.2$ & $82.3 \pm 2.5$ & $(119)^{\#}$ \\
\hline MDA (nmoles/g liver) & $\mathrm{p}<0.01$ & $100.8 \pm 4.5$ & $120.5 \pm 2.5 \quad(120)$ & $141.3 \pm 6.0(140)^{*}$ & $170.8 \pm 14.5$ & $(169)^{\#}$ \\
\hline GSH (umoles/g liver) & $\mathrm{p}<0.01$ & $3.04 \pm 0.24$ & $3.28 \pm 0.02(108)$ & $4.68 \pm 0.31(154)$ & $5.15 \pm 0.54$ & $(169)^{\#}$ \\
\hline
\end{tabular}

Liver weight was calculated as percent value of body weight. MDA, malondialdehyde. GSH, glutathione. Other legends are as in Tables $1 \mathrm{~A}$ and $1 \mathrm{C}$. 
with the oil. Rats were starved, and $19 \mathrm{hr}$ later were exsanguinated via the abdominal vein. Plasma contents of triglyceride were 98 and $71 \mathrm{mg} / \mathrm{dl}$ in no-treatment rats and 96 and $79 \mathrm{mg} / \mathrm{dl}$ in oil-treated rats. No difference existed between these two groups.

Rats were injected with $\mathrm{CHCl}_{3}$ in dosages of 3,30 or 300 $\mathrm{mg} / \mathrm{kg}$. Changes in plasma substances and liver $19 \mathrm{hr}$ after the injection are summarized in Tables 2A, 2B, 2C, and 2D. Lipid and apolipoprotein components of VLDL were reduced at $30 \mathrm{mg} / \mathrm{kg}$, and changes in triglyceride and apolipoprotein $\mathrm{Bl}$ were significant (Table 2A). Components of VLDL were reduced to 20 , or $36 \%$ of the control value at $300 \mathrm{mg} / \mathrm{kg}$. $\mathrm{CHCl}_{3}$ at $3 \mathrm{mg} / \mathrm{kg}$ increased LDL components slightly, but at $30 \mathrm{mg} / \mathrm{kg}$ exerted no effect on $\mathrm{LDL}, \mathrm{HDL}_{1}$, and $\mathrm{HDL}_{2}$ (Tables 2B and 2C). $\mathrm{CHCl}_{3}$ reduced these lipoprotein components by 26 to $48 \%$ at $300 \mathrm{mg} / \mathrm{kg}$. No significant change occurred in plasma components and liver at 3 and $30 \mathrm{mg} / \mathrm{kg}$ except plasma triglyceride (Table 2D). At a dosage of $300 \mathrm{mg} / \mathrm{kg}$ significant decreases in plasma triglyceride and cholesterol were observed. Plasma GPT increased significantly at the same dosage. Increases in liver weight, and in triglyceride, MDA, and GSH in the liver also were significant at the same dosage.

Rats were treated i.p. with $\mathrm{CH}_{2} \mathrm{Cl}_{2}$ in dosages of 300 or $1,000 \mathrm{mg} / \mathrm{kg}$. Changes in plasma substances and liver $8 \mathrm{hr}$ after the treatment are summarized in Tables 3A, 3B, 3C, and 3D. $\mathrm{CH}_{2} \mathrm{Cl}_{2}$ at $300 \mathrm{mg} / \mathrm{kg}$ exerted a little effect on each concentration of VLDL components, e.g., triglyceride, protein, apolipoproteins B1, Bs, E's, and C's (Table 3A). These components were reduced with no statistical significance. At a dosage of $1,000 \mathrm{mg} / \mathrm{kg}, \mathrm{CH}_{2} \mathrm{Cl}_{2}$ reduced concentrations of triglyceride, total protein, and 4 apolipoprotein components of VLDL. Statistical significance was obtained in all items except triglyceride. $\mathrm{CH}_{2} \mathrm{Cl}_{2}$ exerted no effect on $\mathrm{LDL}$ and $\mathrm{HDL}_{1}$ components at $300 \mathrm{mg} / \mathrm{kg}$ (Table 3B). At $1,000 \mathrm{mg} / \mathrm{kg}$, however, LDL lipids, apolipoproteins $\mathrm{Bl}$ and Bs increased 511 to $658 \%$ of control values. $\mathrm{HDL}_{1}$ lipids and apolipoprotein E's increased 244 to $313 \%$ of control values. Total protein concentration of LDL fraction (LDL $+\mathrm{HDL}_{1}$ ) was increased to $361 \%$ of control. As Table $3 \mathrm{C}$ shows, lipid and apolipoprotein components of HDL fraction were reduced to the same degree at both 300 and $1,000 \mathrm{mg} /$ $\mathrm{kg}$. No significant changes were observed in any determination of plasma components and liver at $300 \mathrm{mg} /$ $\mathrm{kg}$ (Table 3D). Plasma GPT activity increased by $286 \%$ at $1,000 \mathrm{mg} / \mathrm{kg}$. Liver weight and liver contents of triglyceride, cholesterol, and phospholipid were reduced. GSH concentration in the liver was reduced to almost half of the control value. No significant changes occurred in MDA concentration.

\section{Discussion}

In their previous report, the authors described changes in lipoproteins of rat plasma following a single i.p. administration of $\mathrm{CCl}_{4}$, trichloroethylene, and 1,1,1trichloroethane $\mathrm{e}^{21)}$. In the present experiments, plasma concentrations of lipoproteins were found to be affected by an i.p. administration of $\mathrm{CHCl}_{3}$ and $\mathrm{CH}_{2} \mathrm{Cl}_{2}$ as well as $\mathrm{CCl}_{4}$.

Present time-course studies revealed that the maximum changes in plasma components and liver substances occurred between 19 and $32 \mathrm{hr}$ following the injection of $\mathrm{CCl}_{4}$ or $\mathrm{CHCl}_{3}$ at 10 or $100 \mathrm{mg} / \mathrm{kg}$, respectively. With $\mathrm{CH}_{2} \mathrm{Cl}_{2}$ at $600 \mathrm{mg} / \mathrm{kg}$, maximal changes in these parameters were produced between 8 and $19 \mathrm{hr}$ following the injection. From these data, $19 \mathrm{hr}$ was chosen for $\mathrm{CCl}_{4}$ and $\mathrm{CHCl}_{3}$ as an interval between the administration of solvents and the sacrifice of rats, and $8 \mathrm{hr}$ was chosen for $\mathrm{CH}_{2} \mathrm{Cl}_{2}$.

Effects of $\mathrm{CCl}_{4}$ on VLDL were almost the same at both 19 and $32 \mathrm{hr}$. Similar tendencies were observed in effects of $\mathrm{CCl}_{4}$ on LDL, plasma triglyceride, liver weight, and liver MDA. $\mathrm{CHCl}_{3}$ exerted almost the same effects at both 19 and $32 \mathrm{hr}$ on liver weight. The effects of $\mathrm{CCl}_{4}$ seemed to be long-lasting compared to those of $\mathrm{CHCl}_{3}$, even though the dose of $\mathrm{CHCl}_{3}$ was ten times higher than that of $\mathrm{CCl}_{4}$. Though statistical significance was not obtained, increases in liver triglyceride induced by $\mathrm{CCl}_{4}$ and $\mathrm{CHCl}_{3}$ reached maximum at 19 to $32 \mathrm{hr}$. This increase indicates a lipid accumulation due to an inhibition of lipid metabolism by $\mathrm{CCl}_{4}$ and $\mathrm{CHCl}_{3}{ }^{16,17)}$. Effects of $\mathrm{CH}_{2} \mathrm{Cl}_{2}$ reached their peak at $8 \mathrm{hr}$ in almost all parameters, while changes in VLDL and liver weight were almost the same at both 8 and $19 \mathrm{hr}$. Changes in $\mathrm{HDL}$ induced by $\mathrm{CH}_{2} \mathrm{Cl}_{2}$ were maximal at $19 \mathrm{hr}$ rather than $8 \mathrm{hr}$. The effects of $\mathrm{CH}_{2} \mathrm{Cl}_{2}$ seemed to be short-lasting compared with those of $\mathrm{CHCl}_{3}$ and $\mathrm{CH}_{2} \mathrm{Cl}_{2}$, while a higher dosage of $\mathrm{CH}_{2} \mathrm{Cl}_{2}$ compared to the other two solvents was needed to exert effects on plasma and liver.

In dose-effect relationship study, $\mathrm{CCl}_{4}$ increased liverto-body weight ratio, liver content of triglyceride, and MDA concentration in the liver at a dosage of $30 \mathrm{mg} / \mathrm{kg}$. Slight increases in these items were observed at a very low dosage of $3 \mathrm{mg} / \mathrm{kg}$. Accumulation of hepatic triglyceride by $\mathrm{CCl}_{4}$ is considered to be a result of the inhibition of lipoprotein excretion from the liver to the blood stream ${ }^{16,17,21)}$. This scheme clearly explains the decrease in plasma lipids and lipoproteins, as well as the increase in hepatic triglyceride 
Table 2A. Effects of a single administration of chloroform on the plasma VLDL fraction of rats

\begin{tabular}{lccccc}
\hline \multicolumn{1}{c}{ Dose (mg/kg) } & F-test & 0 & 3 & 30 & 300 \\
\hline TG (mg/dl plasma) & $\mathrm{p}<0.01$ & $84.8 \pm 3.6$ & $78.0 \pm 2.1(92)$ & $54.8 \pm 2.9(65)^{\#}$ & $30.8 \pm 5.4(36)^{\#}$ \\
PR (mg/dl plasma) & $\mathrm{p}<0.01$ & $13.5 \pm 0.4$ & $13.4 \pm 0.5(99)$ & $12.4 \pm 0.6(92)$ & $3.4 \pm 0.5(25)^{\#}$ \\
Apo Bl (A.U.) & $\mathrm{p}<0.01$ & $23.8 \pm 1.3$ & $20.3 \pm 1.5(85)$ & $18.3 \pm 1.4(77)^{*}$ & $8.3 \pm 1.1(35)^{\#}$ \\
Apo Bs (A.U.) & $\mathrm{p}<0.01$ & $58.5 \pm 3.0$ & $60.3 \pm 3.0(103)$ & $49.3 \pm 2.4(84)$ & $15.0 \pm 1.4(26)^{\#}$ \\
Apo E's (A.U.) & $\mathrm{p}<0.01$ & $195.5 \pm 12.5$ & $190.3 \pm 8.5(97)$ & $183.3 \pm 11.1(94)$ & $39.0 \pm 5.1(20)^{\#}$ \\
Apo C's (A.U.) & $\mathrm{p}<0.01$ & $127.5 \pm 6.0$ & $125.5 \pm 5.7(98)$ & $119.3 \pm 7.9(94)$ & $39.3 \pm 5.1(31)^{\#}$ \\
\hline
\end{tabular}

Legends are as in Table $1 \mathrm{~A}$.

Table 2B. Effects of a single administration of chloroform on the plasma LDL fraction of rats

\begin{tabular}{|c|c|c|c|c|c|}
\hline Dose $(\mathrm{mg} / \mathrm{kg})$ & F-test & 0 & 3 & 30 & 300 \\
\hline \multicolumn{6}{|l|}{ LDL } \\
\hline Lipid (A.U.) & $\mathrm{p}<0.01$ & $167.0 \pm 5.8$ & $193.8 \pm 15.5(116)$ & $164.5 \pm 10.5(99)$ & $115.8 \pm 9.0$ \\
\hline Apo Bl (A.U.) & $\mathrm{p}<0.01$ & $121.8 \pm 4.5$ & $146.0 \pm 6.5$ & $128.3 \pm 10.0(105)$ & $90.3 \pm 8.7(74)^{*}$ \\
\hline Apo Bs (A.U.) & $\mathrm{p}<0.01$ & $23.0 \pm 1.9$ & $32.0 \pm 3.8$ & $23.0 \pm 0.4 \quad(100)$ & $12.0 \pm 1.7 \quad(52)^{*}$ \\
\hline \multicolumn{6}{|l|}{$\mathrm{HDL}_{1}$} \\
\hline Lipid (A.U.) & $\mathrm{p}<0.01$ & $106.0 \pm 6.6$ & $97.5 \pm 5.6(92)$ & $94.5 \pm 4.9 \quad(89)$ & $59.5 \pm 3.3(56)^{\#}$ \\
\hline Apo E's (A.U.) & $\mathrm{p}<0.01$ & $173.3 \pm 7.7$ & $170.3 \pm 4.0 \quad(98)$ & $165.8 \pm 6.4 \quad(96)$ & $111.3 \pm 4.0$ \\
\hline \multicolumn{6}{|l|}{$\mathrm{LDL}+\mathrm{HDL}_{1}$} \\
\hline PR (mg/dl plasma) & $\mathrm{p}<0.01$ & $2.68 \pm 0.13$ & $2.68 \pm 0.10(100)$ & $2.55 \pm 0.21(95)$ & $1.73 \pm 0.17(65)^{\#}$ \\
\hline
\end{tabular}

Legends are as in Table $1 \mathrm{~B}$.

Table 2C. Effects of a single administration of chloroform on the plasma HDL fraction of rats

\begin{tabular}{lccccc}
\hline \multicolumn{1}{c}{ Dose (mg/kg) } & F-test & 0 & 3 & 30 & 300 \\
\hline CH (mg/dl plasma) & $\mathrm{p}<0.01$ & $25.3 \pm 1.3$ & $26.0 \pm 1.7(103)$ & $22.8 \pm 0.6(90)$ & $15.0 \pm 1.1(59)^{\#}$ \\
PL (mg/dl plasma) & $\mathrm{p}<0.01$ & $24.8 \pm 0.6$ & $24.5 \pm 0.9(99)$ & $23.3 \pm 0.5(94)$ & $14.3 \pm 0.5(58)^{\#}$ \\
PR (mg/dl plasma) & $\mathrm{p}<0.01$ & $74.0 \pm 4.6$ & $73.8 \pm 4.2(100)$ & $74.0 \pm 3.9(100)$ & $47.0 \pm 4.2(64)^{\#}$ \\
Apo A-IV (A.U.) & $\mathrm{p}<0.01$ & $257 \pm 8$ & $252 \pm 7 \quad(98)$ & $249 \pm 5(97)$ & $139 \pm 11(54)^{\#}$ \\
Apo E's (A.U.) & $\mathrm{p}<0.01$ & $1,174 \pm 67$ & $1,192 \pm 53(102)$ & $1,245 \pm 66(106)$ & $646 \pm 65(55)^{\#}$ \\
Apo A-I (A.U.) & $\mathrm{p}<0.01$ & $2,324 \pm 87$ & $2,346 \pm 97(101)$ & $2,359 \pm 71(102)$ & $1,238 \pm 152(53)^{\#}$ \\
Apo C's (A.U.) & $\mathrm{p}<0.01$ & $637 \pm 32$ & $700 \pm 32(110)$ & $717 \pm 55(113)$ & $376 \pm 18(59)^{\#}$ \\
\hline
\end{tabular}

Legends are as in Table 1C.

Table 2D. Effects of a single administration of chloroform on the plasma lipid contents, GPT activity, and liver of rats

\begin{tabular}{lccccc}
\hline \multicolumn{1}{c}{ Dose (mg/kg) } & F-test & 0 & 3 & 30 & 300 \\
\hline Plasma & & & & & \\
TG (mg/dl plasma) & $\mathrm{p}<0.01$ & $123.5 \pm 6.0$ & $117.0 \pm 4.3(95)$ & $95.3 \pm 5.4(77)^{*}$ & $53.0 \pm 11.4(43)^{\#}$ \\
CH (mg/dl plasma) & $\mathrm{p}<0.01$ & $63.3 \pm 3.8$ & $65.3 \pm 4.4(103)$ & $61.5 \pm 2.6(97)$ & $38.8 \pm 1.7(61)^{\#}$ \\
GPT (IU/L) & $\mathrm{p}<0.01$ & $44.5 \pm 2.9$ & $43.5 \pm 2.6(98)$ & $52.8 \pm 2.9(119)$ & $388.5 \pm 66.9(873)^{\#}$ \\
Liver & & & & & \\
Weight (\%) & $\mathrm{p}<0.05$ & $2.64 \pm 0.06$ & $2.64 \pm 0.04(100)$ & $2.70 \pm 0.07(102)$ & $2.96 \pm 0.07(110)^{*}$ \\
TG (mg/liver) & $\mathrm{p}<0.01$ & $63.5 \pm 3.7$ & $63.5 \pm 3.2(100)$ & $66.5 \pm 1.7(105)$ & $103.8 \pm 7.6(164)^{\#}$ \\
CH (mg/liver) & n.s. & $46.8 \pm 3.1$ & $47.8 \pm 2.1 \quad(102)$ & $47.3 \pm 0.9(101)$ & $51.5 \pm 2.1(110)$ \\
PL (mg/liver) & n.s. & $68.0 \pm 4.9$ & $69.8 \pm 3.0(103)$ & $69.3 \pm 1.1(102)$ & $72.3 \pm 3.0(106)$ \\
MDA (nmoles/g liver) & p<0.05 & $124.8 \pm 10.0$ & $125.0 \pm 6.0(100)$ & $137.8 \pm 7.8(110)$ & $164.5 \pm 7.5(132)^{*}$ \\
GSH (umoles/g liver) & p<0.01 & $4.43 \pm 0.22$ & $4.30 \pm 0.18(97)$ & $4.60 \pm 0.27(104)$ & $6.78 \pm 0.58(153)^{\#}$ \\
\hline
\end{tabular}

Legends are as in Table 1D. 
Table 3A. Effects of a single administration of dichloromethane on the plasma VLDL fraction of rats

\begin{tabular}{lcrrrl}
\hline \multicolumn{1}{c}{ Dose (mg/kg) } & F-test & \multicolumn{1}{c}{0} & 300 & \multicolumn{1}{c}{1,000} \\
\hline TG (mg/dl plasma) & n.s. & $64.0 \pm 3.3$ & $54.0 \pm 5.2(84)$ & $46.5 \pm 8.8(73)$ \\
PR (mg/dl plasma) & p $<0.01$ & $9.8 \pm 0.6$ & $9.3 \pm 0.8 \quad(95)$ & $5.5 \pm 0.4(56)^{*}$ \\
Apo Bl (A.U.) & p $<0.05$ & $19.5 \pm 1.3$ & $15.5 \pm 2.0(80)$ & $12.0 \pm 0.4(62)^{\#}$ \\
Apo Bs (A.U.) & p $<0.01$ & $46.5 \pm 1.8$ & $39.5 \pm 3.8(85)$ & $26.0 \pm 2.2(56)^{\#}$ \\
Apo E's (A.U.) & p $<0.01$ & $170.3 \pm 8.2$ & $156.3 \pm 23.7(92)$ & $82.5 \pm 11.4(48)^{\#}$ \\
Apo C's (A.U.) & p $<0.05$ & $91.8 \pm 5.2$ & $70.3 \pm 6.9(77)$ & $59.0 \pm 5.9 \quad(64)^{*}$ \\
\hline
\end{tabular}

Legends are as in Table $1 \mathrm{~A}$.

Table 3B. Effects of a single administration of dichloromethane on the plasma LDL fraction of rats

\begin{tabular}{lcccc}
\hline Dose (mg/kg) & F-test & 0 & 300 & 1,000 \\
\hline LDL & & & & \\
Lipid (A.U.) & $\mathrm{p}<0.01$ & $137.8 \pm 7.4$ & $143.0 \pm 12.7(104)$ & $771.5 \pm 81.7(560)^{\#}$ \\
Apo Bl (A.U.) & $\mathrm{p}<0.01$ & $90.8 \pm 6.1$ & $84.5 \pm 6.0(93)$ & $464.0 \pm 30.9(511)^{\#}$ \\
Apo Bs (A.U.) & $\mathrm{p}<0.01$ & $12.5 \pm 0.6$ & $12.5 \pm 1.3 \quad(100)$ & $82.3 \pm 3.9(658)^{\#}$ \\
HDL & & & & \\
$\quad$ Lipid (A.U.) & $\mathrm{p}<0.01$ & $73.5 \pm 4.2$ & $86.5 \pm 5.0(118)$ & $230.0 \pm 24.1(313)^{\#}$ \\
Apo E's (A.U.) & $\mathrm{p}<0.01$ & $182.8 \pm 12.3$ & $184.0 \pm 9.1 \quad(101)$ & $446.8 \pm 51.4(244)^{\#}$ \\
LDL + HDL & & & & \\
PR (mg/dl plasma) & $\mathrm{p}<0.01$ & $3.1 \pm 0.1$ & $3.0 \pm 0.2(97)$ & $11.2 \pm 1.0(361)^{\#}$ \\
\hline
\end{tabular}

Legends are as in Table 1B.

Table 3C. Effects of a single administration of dichloromethane on the plasma HDL fraction of rats

\begin{tabular}{lcccc}
\hline \multicolumn{1}{c}{ Dose (mg/kg) } & F-test & 0 & 300 & 1,000 \\
\hline CH (mg/dl plasma) & p $<0.01$ & $25.8 \pm 0.9$ & $18.3 \pm 0.9(71)^{\#}$ & $19.8 \pm 1.9(77)^{*}$ \\
PL (mg/dl plasma) & p $<0.01$ & $26.5 \pm 1.7$ & $20.0 \pm 2.0(76)$ & $23.0 \pm 2.7(87)$ \\
PR (mg/dl plasma) & n.s. & $61.0 \pm 3.0$ & $47.8 \pm 1.5(78)^{\#}$ & $45.8 \pm 2.7(75)^{\#}$ \\
Apo A-IV (A.U.) & n.s. & $209 \pm 14$ & $149 \pm 20(71)$ & $174 \pm 14(83)$ \\
Apo E's (A.U.) & n.s. & $1,290 \pm 68$ & $1,079 \pm 49(84)$ & $1,117 \pm 67(87)$ \\
Apo A-I (A.U.) & p<0.01 & $1,866 \pm 88$ & $1,148 \pm 66(62)^{\#}$ & $1,288 \pm 184(69)^{*}$ \\
Apo C's (A.U.) & n.s. & $466 \pm 38$ & $388 \pm 66(83)$ & $403 \pm 32(87)$ \\
\hline
\end{tabular}

Legends are as in Table 1C.

Table 3D. Effects of a single administration of dichloromethane on plasma lipid contents, GPT activity, and liver of rats

\begin{tabular}{lcccc}
\hline Dose (mg/kg) & F-test & 0 & 300 & 1,000 \\
\hline Plasma & & & & \\
TG (mg/dl plasma) & p $<0.01$ & $85.0 \pm 2.9$ & $70.8 \pm 11.6(83)$ & $66.3 \pm 4.2 \quad(78)$ \\
CH (mg/dl plasma) & n.s. & $64.3 \pm 5.3$ & $54.3 \pm 4.1(84)$ & $57.8 \pm 8.5(90)$ \\
GPT (IU/L) & p $<0.01$ & $30.8 \pm 3.1$ & $39.3 \pm 2.5(128)$ & $119.0 \pm 8.9(386)^{\#}$ \\
Liver & & & & \\
Weight (\%) & p<0.05 & $2.52 \pm 0.05$ & $2.31 \pm 0.08(92)$ & $2.25 \pm 0.05(89)^{*}$ \\
TG (mg/liver) & p<0.05 & $44.0 \pm 2.7$ & $39.5 \pm 2.6(90)$ & $31.8 \pm 1.5(72)^{\#}$ \\
CH (mg/liver) & p<0.05 & $28.0 \pm 1.9$ & $27.5 \pm 1.3(98)$ & $22.0 \pm 1.6(79)^{*}$ \\
PL (mg/liver) & p<0.01 & $94.0 \pm 5.2$ & $83.8 \pm 2.9(89)$ & $74.5 \pm 2.7(79)^{\#}$ \\
MDA (nmoles/g liver) & n.s. & $104.5 \pm 6.5$ & $107.3 \pm 13.6(103)$ & $90.3 \pm 4.3(86)$ \\
GSH (umoles/g liver) & p<0.01 & $4.28 \pm 0.36$ & $3.85 \pm 0.41(90)$ & $2.53 \pm 0.15(59)^{\#}$ \\
\hline
\end{tabular}

Legends are as in Table 1D. 
by $\mathrm{CCl}_{4}$ observed in the current study. MDA is thought to be a good indicator of lipid peroxide production ${ }^{23)}$. Lipid peroxide is one of main causes of liver injury produced by $\mathrm{CCl}_{4}{ }^{12)}$. In the current study, MDA was increased by $\mathrm{CCl}_{4}$ at $30 \mathrm{mg} / \mathrm{kg}$, while changes in plasma GPT were not significant at this dosage. A dosage of $300 \mathrm{mg} / \mathrm{kg}$ of $\mathrm{CCl}_{4}$ was needed to increase GPT activity significantly. Distinct decreases in plasma lipids and lipoproteins induced by $\mathrm{CCl}_{4}$ at $30 \mathrm{mg} / \mathrm{kg}$ suggest that decreases in these items are more sensitive indicators of liver damage due to $\mathrm{CCl}_{4}$ than traditional markers such as GPT.

Among various plasma lipoproteins, components of VLDL, e.g., triglyceride, protein, and apolipoprotein C's, decreased significantly with an i.p. administration of $\mathrm{CCl}_{4}$ at $3 \mathrm{mg} / \mathrm{kg}$ or more. All components of LDL fraction and some components of HDL fraction decreased significantly with $\mathrm{CCl}_{4}$ at $30 \mathrm{mg} / \mathrm{kg}$ or more. Total triglyceride and cholesterol concentrations in plasma decreased significantly with $\mathrm{CCl}_{4}$ at $30 \mathrm{mg} / \mathrm{kg}$ or more, while these lipids in plasma exerted no change at $3 \mathrm{mg} / \mathrm{kg}$ of $\mathrm{CCl}_{4}$. On the other hand, components of VLDL decreased significantly at $3 \mathrm{mg} / \mathrm{kg}$, which indicates that an analysis of lipoprotein components, particularly of VLDL, can reveal sensitive markers regarding $\mathrm{CCl}_{4}$ toxicity.

An administration of $\mathrm{CHCl}_{3}$ at $30 \mathrm{mg} / \mathrm{kg}$ produced significant decreases in plasma triglyceride and apolipoprotein Bl of VLDL fraction. Significant increase in GPT activity was observed at $300 \mathrm{mg} / \mathrm{kg}$ and not at 30 $\mathrm{mg} / \mathrm{kg}$. These results mean that plasma triglyceride and VLDL are more sensitive markers than GPT for $\mathrm{CHCl}_{3}$ exposure.

$\mathrm{CH}_{2} \mathrm{Cl}_{2}$ reduced VLDL components slightly at $300 \mathrm{mg} /$ $\mathrm{kg}$ and significantly at $1,000 \mathrm{mg} / \mathrm{kg}$, and significant decreases in HDL components occurred at $300 \mathrm{mg} / \mathrm{kg}$. As an increase in GPT activity was observed at $1,000 \mathrm{mg} / \mathrm{kg}$, the decrease in $\mathrm{HDL}$ was a more sensitive marker for exposure to $\mathrm{CH}_{2} \mathrm{Cl}_{2}$ than plasma GPT. A large increase in LDL was observed following exposure to $1,000 \mathrm{mg} / \mathrm{kg}$ of $\mathrm{CH}_{2} \mathrm{Cl}_{2}$. Plasma LDL was increased following i.p. administration of trichloroethylene and 1,1,1-trichloroethane $\mathrm{e}^{21}$. In this study, a slight increase in LDL was induced by $\mathrm{CCl}_{4}$ and $\mathrm{CHCl}_{3}$ at $3 \mathrm{mg} / \mathrm{kg}$. LDL increases induced by these chemicals, however, were not so marked as those observed after an injection of $\mathrm{CH}_{2} \mathrm{Cl}_{2}$. A marked increase in LDL seems to be characteristic for injections of high dosages of $\mathrm{CH}_{2} \mathrm{Cl}_{2}$.

Hepatic triglyceride is excreted to the blood stream as a component of VLDL ${ }^{26)}$. VLDL particles in the blood lose triglyceride under the action of lipase, etc., and is converted into LDL, which is then absorbed into the liver ${ }^{27}$. Details of the synthesis of HDL is not known but most HDL is thought to be synthesized in the liver. According to Lombardi and Ugazio ${ }^{17)}, \mathrm{CCl}_{4}$ inhibits the synthesis of apolipoproteins in the liver. Due to this lack of apolipoprotein components, the synthesis of lipoproteins is disturbed, and excretion of lipoproteins from the liver to the blood stream is inhibited. This is the main scheme of the decrease in plasma lipoproteins and the increase in hepatic triglyceride. The results obtained in the current study that the decrease in VLDL and LDL by $\mathrm{CCl}_{4}$ is accompanied by the increase in hepatic triglyceride, are well consistent with this scheme. The results of the current study show that changes in plasma lipoproteins serve as markers for liver dysfunction in addition to playing the role of exposure markers. The present results also indicate that the synthesis inhibition of lipoproteins probably occurs at much lower dosages of $\mathrm{CCl}_{4}, \mathrm{CHCl}_{3}$, and $\mathrm{CH}_{2} \mathrm{Cl}_{2}$ than the dosages at which the leaking of GPT molecule from hepatic cells occurs, which indicates that changes in plasma lipoproteins are sensitive as hepatotoxicity markers.

With the administration of $\mathrm{CHCl}_{3}$, all lipoprotein fractions decreased. $\mathrm{CHCl}_{3}$ induced these effects at higher dosages than those where $\mathrm{CCl}_{4}$ decreased lipoproteins. While $\mathrm{CHCl}_{3}$ appears to inhibit lipoprotein metabolism as $\mathrm{CCl}_{4}$ does, $\mathrm{CHCl}_{3}$ is less potent than $\mathrm{CCl}_{4}$.

$\mathrm{CH}_{2} \mathrm{Cl}_{2}$ decreased plasma VLDL and HDL, whereas it increased LDL at $1,000 \mathrm{mg} / \mathrm{kg}$. It is not known what chemicals produce such phenomena. Plasma LDL disappears from the blood stream by an uptake of LDL into the liver via LDL receptors on the liver's surface ${ }^{27}$. The uptake of LDL into the liver may be strongly inhibited by $\mathrm{CH}_{2} \mathrm{Cl}_{2}$. However, the mechanism of the LDL increase observed in this study remains unclear. High dosages of $\mathrm{CH}_{2} \mathrm{Cl}_{2}$ increased $\mathrm{HDL}_{1}$, although the degree of the increase was less than that of LDL. As HDL $\mathrm{H}_{1}$ does not exist in normal human blood, the study on the metabolism of $\mathrm{HDL}_{1}$ did not make any significant discoveries. At present, it is difficult to explain the mechanism of increase in $\mathrm{HDL}_{1}$ by $\mathrm{CH}_{2} \mathrm{Cl}_{2}$.

Our present study showed that i.p. administration of chlorinated organic solvents produced different changes in the lipoproteins in the blood. Many of these changes occurred at lower dosages than those where GPT activity was elevated. Different changes in the liver occurred at the dosages where changes in lipoproteins occurred than those dosages where GPT activity was elevated. These findings indicate that changes in plasma lipoproteins are closely related with liver dysfunction. Study on the mechanism of this relationship is in progress. 


\section{Acknowledgments}

The authors wish to express their gratitude and appreciation to Ms. Kikue Sugisaki, Mr. Akira Furuya, Mr. Naoyuki Kokubo, and Mr. Tohru Ozawa, for their technical assistance.

\section{References}

1) Browning $E$ (1965) Toxicity and metabolism of industrial solvents. 172-275, Elsevier, Amsterdam.

2) IARC (1986) IARC Monographs, Vol 41. Some halogenated hydrocarbons and pesticide exposures. IARC/WHO, Lyon.

3) Torkelson TR (1994) Halogenated aliphatic hydrocarbons containing chlorine, bromine, and iodine. In: Patty's industrial hygiene and toxicology. 4th ed. vol II, Part E, Toxicology. ed. by Clayton GD, Clayton FE, 4007-251, John Wiley \& Sons, New York.

4) Plaa GL, Evans EA, Hine CH (1958) Relative hepatotoxicity of seven halogenated hydrocarbons. $\mathrm{J}$ Pharmacol Exp Ther 123, 224-9.

5) Klaassen CD, Plaa GL (1966) Relative effects of verious chlorinated hydrocarbon on liver and kidney function in mice. Toxicol Appl Pharmacol 9, 139-51.

6) Recknagel RO (1967) Carbon tetrachloride hepatotoxicity. Pharmacol Rev 19, 145-208.

7) IARC (1979) IARC Monographs, Vol 20. Some halogenated hydrocarbons. 371-99, IARC/WHO, Lyon.

8) IARC (1979) IARC Monographs, Vol 20. Some halogenated hydrocarbons. 401-27, IARC/WHO, Lyon.

9) Agency for Toxic Substances and Disease Registry (1992) Carbon tetrachloride toxicity. Am Fam Physician 46, 1199-207.

10) Gehring PJ (1968) Hepatotoxic potency of various chlorinated hydrocarbon vapours relative to their narcotic and lethal potencies in mice. Toxicol Appl Pharmacol 13, 287-98.

11) Seppalainen AM (1985) Halogenated hydrocarbons. In: Neurotoxicology. ed. by Blum K, Manzo L, Marcel Dekker, Inc., New York and Basel.

12) Recknagel RO, Glende EA Jr, Dolak JA, Waller RL (1989) Mechanism of carbon tetrachloride toxicity. Pharmac Ther 43, 139-54.

13) Mansuy $D$, Beaune $P$, Crestell $T$, Lange $M$, Leroux J-P (1977) Evidence for phosgene formation during liver microsomal oxidation of chloroform. Biochem Biophys Res Commun 79, 513-7.

14) Recknagel RO, Lombardi B, Schotz MC (1960) A new insight into pathogenesis of carbon tetrachloride fat infiltration. Proc Soc Exp Biol Med 104, 608-10.

15) Recknagel RO, Lombardi B (1960) Studies of biochemical changes in subcellular particles of rat liver and their relationship to a new hypothesis regarding the pathogenesis of carbon tetrachloride fat accumulation. J Biol Chem 236, 564-9.

16) Seakins A, Robinson DS (1963) The effect of the administration of carbon tetrachloride on the formation of plasma lipoproteins in the rat. Biochem J 86, 401-7.

17) Lombardi B, Ugazio G (1965) Serum lipoproteins in rats with carbon tetrachloride-induced fatty liver. J Lipid Res 6, 498-505.

18) Honma T, Ohtani K (1994) Plasma lipoproteins as hepatotoxicity markers for chlorinated organic solvents. International Symposium on Human Risk and Environment. Salsomaggiore Terme (Italy), Programme and Abstracts 143.

19) Honma $T$, Miyagawa $M$ (1988) Effects of organic solvents on rat lipoproteins. Jpn J Ind Health 30, 660.

20) Honma T, Sato M (1989) Changes in plasma lipoproteins and liver of rats induced by organic solvents. Jpn J Ind Health 31, 693.

21) Honma $T$ (1990) Effects of trichloroethylene, 1,1,1trichloroethane and carbon tetrachloride on plasma lipoproteins of rats. Ind Health 28, 159-74.

22) Folch J, Lee M, Stanley GHS (1957) A simple method for the isolation and purification of total lipids from animal tissues. J Biol Chem 226, 497-509.

23) Yagi $K$ (1976) A simple fluorometric assay for lipoperoxide in blood plasma. Biochem Med 15, 2126.

24) Sies H, Akerboom TPM (1984) Glutathione disulfide (GSSG) efflux from cells and tissues. Methods in Enz 105, 445-51.

25) Hartree EF (1972) Determination of protein. A modification of the Lowry method that gives a linear photometric response. Anal Biochem 48, 422-7.

26) Boren J, Wettesten $M$, Sjoberg A, Thorlin T, Bondjers G, Wiklund O, Olofsson S-O (1990) The assembly and secretion of apo B100 containing lipoproteins in HepG2 cells. Evidence for different sites for protein synthesis and lipoprotein assembly. J Biol Chem 265 , 10556-64.

27) Brown MS, Kovanen PT, Goldstein JL (1981) Regulation of plasma cholesterol by lipoprotein receptors. Science 212, 628-35. 